\title{
Clinical profile of patients admitted to the PICU of a tertiary care teaching hospital
}

\author{
Mukhija G ${ }^{1}$, Chandra $S^{2}$, Prasad P.L $L^{3}$ \\ ${ }^{1}$ Dr. Gaurav Mukhija, ${ }^{2}$ Dr Surabhi Chandra, ${ }^{3}$ Dr PL Prasad, all authors are affiliated with Department of Pediatrics, \\ SRMS Institute of Medical Sciences, Bareilly, UP, India.
}

Address for Correspondence: Dr Surabhi Chandra, Department of Pediatrics, SRMS-IMS, Bhojipura, Bareilly. Email id: surabhi0329@gmail.com

\begin{abstract}
Introduction: There is a dearth of data on the clinical and etiological spectrum of PICU (Pediatric Intensive Care Unit) admissions from India, especially from post graduation teaching institutes. Aim: The current study was undertaken to study the clinical profile of patients admitted to the PICU of a tertiary care post graduation teaching institute. Materials and Methods: This was a prospective observational study done over 6 months (June - Nov 2016) in the PICU of a tertiary care teaching hospital, where critically ill children were admitted and observations recorded. Data was later analyzed using the Epi-info software version 7.5.1. Results: A total of 287 patients were admitted of whom majority were males and belonged to the rural areas. Most common clinical indication for PICU admission was respiratory (46.2\%) and the most common single primary diagnosis was sepsis (40.06\%). MODS (44.3\%) was the major comorbidity. The major procedure done was endo-tracheal intubation in $66.2 \%(190 / 287)$ patients. Majority $86.7 \%$ (249/287) patients improved, were shifted to ward and later discharged. Death occurred in 8.0\% (23/287). Conclusion: Clinical profile of patients admitted to our PICU was similar to that of other hospitals.
\end{abstract}

Keywords: Critically ill patients, Pediatric Intensive Care Unit, MODS

\section{Introduction}

Pediatric Intensive Care is commonly practised in India both at the pediatric superspeciality and pediatric post graduation level. However, there is a dearth of data on the clinical and etiological spectrum of PICU (Pediatric Intensive Care Unit) admissions from India [1], specially from post graduation teaching institutes. Knowledge of this data, can help the paediatricians and the pediatric intensivists in tailor making the PICUs more adaptive for the Indian patients in general and the population they cater to, in specific.

The current study was undertaken to study the clinical profile of patients admitted to the PICU of a tertiary care post graduation teaching institute.

\section{Materials and Methods}

This was a prospective observational study, carried out in the PICU of a tertiary care post graduation teaching

Manuscript received: $6^{\text {th }}$ February 2017

Reviewed: $14^{\text {th }}$ February 2017

Author Corrected: $20^{\text {th }}$ February 2017

Accepted for Publication: $28^{\text {th }}$ February 2017 institute of North India, over a duration of six months (June 2016 - November 2016). On the basis of yearly PICU admissions of approximately 850-900 children, a minimum sample size of 250 patients (over 6 months) was deduced. 'Critically ill children' (Between 1 month - 12 years of age) admitted to the PICU were enrolled in the study. Children whose parents did not consent were excluded.

'Critically ill children' were defined as having at least one of the following criteria;

a) Respiratory - Abnormal respiratory rate ( $>$ or $<=$ 2SD - Standard Deviation expected for age and sex)/gasping/Not maintaining respiration.

b) Cardiovascular - Abnormal heart rate ( $>$ or $<=$ 2SD expected for age and sex).

Or Shock (Blood pressure $<5^{\text {th }}$ percentile for age and sex) or Hypertension (Blood pressure $>95^{\text {th }}$ percentile for age and sex). 
c) Central Nervous System - Status epilepticus, Altered sensorium / Encephalopathy, Raised intracranial pressure.

d) Others

Sepsis, MODS (Multi Organ dysfunction Syndrome), Acute Kidney Injury, Hospital Acquired Infection (HAI), Ventilator Associated Pneumonia (VAP), nosocomial Urinary Tract Infection (UTI) and Catheter Related Blood Stream Infection (CRBSI) were defined as per standard definitions [2].

Demographic and clinical details were recorded onto a predesigned data collection pro forma and data was later entered into an MS-Excel 2007 spreadsheet. Analysis was done using the statistical software Epiinfo version 7.5.1. Continuous data was represented as Mean and SD, while discrete data was represented as frequencies.

\section{Results}

A total of 287 patients were admitted to the PICU during June 2016- November 2016. Of these 190 patients were males. Mean age of presentation was 96.50 months (Range; $1.0-192.0$ months; SD (Standard Deviation) - 55.09. Majority, approximately $65 \%(188 / 287)$ patients belonged to the rural areas.

Major indication for admission to the PICU was respiratory $(46.2 \%)$, followed by cardiovascular $(41.2 \%)$, central nervous system $(10.8 \%)$ and others $(1.9 \%)$ in that order. The major $(40.06 \%)$ single primary diagnosis was sepsis (excluding central nervous system infections). However the majority $(62.7 \%)$ had a mixed etiology.

One ninety six patients $(68.3 \%)$ required ventilatory support during the course of their PICU stay. Approximately 97\% (190/196) of the ventilated patients were intubated electively.

Ventilator associated pneumonia developed in 21 $(10.7 \%)$ patients of whom $12(4.7 \%)$ patients had already come intubated from elsewhere. Mean duration of ventilator support was 42.34 hours (Range 6-172 hours; SD 37.65).

Shock developed in 53.3\% (153/287) patients sometime during the course of their PICU stay. Septic shock was seen in $47.0 \%(72 / 153)$ patients and hypovolemic in $33.3 \%(51 / 153)$ patients with shock.
Most common co-morbidities developing during the PICU stay were MODS in 44.3\% (127/287), hospital acquired infection (HAI) in $17.1 \%(49 / 287)$ and acute kidney injury in $13.9 \%(40 / 287)$ cases. Most common HAI was VAP $42.8 \%$ (21/49), followed by nosocomial UTI in $30.6 \%(15 / 49)$ and CRBSI in $26.5 \%(13 / 49)$ cases.

The major procedure done was endo-tracheal intubation in $66.2 \%(190 / 287)$ patients followed by lumbar puncture in 25.4\% (73/287). Majority $86.7 \%$ (249/287) patients improved, were shifted to ward and later discharged. Death occurred in 8.0\% (23/287). Fifteen patients $(5.2 \%)$ left treatment in between due to personal reasons.

\section{Discussion}

A recent study aimed at evaluating differences in diagnosis on admission and outcomes between a total of 131 Malaysian and immigrant children, found the leading diagnoses on admission being respiratory (37\%), neurological (18\%) and infectious (17\%) disorders.

The diagnostic category with the maximum mortality was respiratory disorder (22\%) followed by septicaemia (22\%), hemato-oncological (17\%) and neurologic (13\%) disorder in descending order of incidence [3].

Another recent study, from Canada, described the frequency, characteristics and outcomes of children who require early unplanned admission to PICU within 24 hours of hospitalization and found the majority of admissions being infants and respiratory issues being the chief indication for PICU admission. Approximately half of them requiring a significant intervention after admission and a mortality rate of $50 \%$ [4]

A study from Pakistan also found that similar age group was affected the most and primary diagnoses requiring admission had an almost equal distribution between medical (46\%) and surgical (54\%) cases [5].

A 16 year epidemiological profile review of a Brazilian PICU, in the early $21^{\text {st }}$ century concluded that mortality is higher in malnourished infants and that sepsis was the most common cause of death [6].

Another research studied the clinical profile of longstay patients (LSPs) in the PICU and found that majority of them are younger and those that require chronic care device [7]. 
An Indian study, done in the last decade, revealed that septicaemia was the most common indication for PICU admission and the most common clinical condition requiring long term stay in the PICU was meningitis $(20 \%)$. A mortality rate of $23.5 \%$ was seen, with the highest numbers seen in Encephalitis [8].

VAP was the most common hospital acquired infection in or study likely due to the fact that 12 of the total 21 patients who developed VAP, had come intubated from outside.

Acknowledgements-My sincere thanks to Dr Aditi Gupta, $1^{\text {st }}$ Year Junior Resident for assistance in data collection.

Funding: Nil, Conflict of interest: None initiated, Perission from IRB: Yes

\section{References}

1. Khilnani P, Sarma D, Singh R, Uttam R, Rajdev S, Makkar A, Kaur J. Demographic profile and outcome analysis of a tertiary level pediatric intensive care unit. Indian J Pediatr. 2004 Jul;71(7):587-91.

2. Shah NK, Udani S, Chugh K, Ugra D, Khilnani P, editors. IAP Speciality Series on Pediatric intensive Care. $2^{\text {nd }}$ ed. New Delhi: Jaypee Brothers Medical Publishers Ltd; 2013.
3. Ganesan I, Thomas T, Ng FE, Soo TL. Clinical characteristics and mortality risk prediction in critically ill children in Malaysian Borneo. Singapore Med J. 2014 May; 55(5):261-5.

4. Krmpotic K, Lobos AT. Clinical profile of children requiring early unplanned admission to the PICU. Hosp Pediatr. 2013 Jul;3(3):212-8.

5. Haque A, Bano S. Clinical profile and outcome in a paediatric intensive care unit in Pakistan. J Coll Physicians Surg Pak. 2009 Aug;19(8):534-5. doi: 08. 2009 /JCPSP.534535.

6. Einloft PR, Garcia PC, Piva JP, Bruno F, Kipper DJ, Fiori RM. [A sixteen-year epidemiological profile of a pediatric intensive care unit, Brazil]. Rev Saude Publica. 2002 Dec; 36(6):728-33.

7. Marcin JP, Slonim AD, Pollack MM, Ruttimann UE. Long-stay patients in the pediatric intensive care unit. Crit Care Med. 2001 Mar;29(3):652-7.

8. Kapil D, Bagga A. The profile and outcome of patients admitted to a pediatric intensive care unit. Indian J Pediatr. 1993 Jan-Feb;60(1):5-10.

\section{How to cite this article?}

Mukhija G, Chandra S, Prasad P.L. Clinical profile of patients admitted to the PICU of a tertiary care teaching hospital. J PediatrRes.2017;4(02):125-127.doi:10.17511/ijpr.2017.i02.06. 